\title{
Use of English Vocabulary Learning Strategies by Thai Tertiary-Level Students in Relation to Fields of Study and Language-Learning Experiences
}

\author{
Nathaya Boonkongsaen ${ }^{1} \&$ Channarong Intaraprasert ${ }^{1}$ \\ ${ }^{1}$ School of Foreign Languages, Institute of Social Technology, Suranaree University of Technology, Thailand \\ Correspondence: Nathaya Boonkongsaen, School of Foreign Languages, Suranaree University of Technology, 111 \\ University Avenue, Muang District, 30000 Nakhon Ratchasima, Thailand. E-mail: Nathayaatvu@gmail.com
}

Received: February 1, 2014 Accepted: March 6, 2014 Online Published: April 14, 2014

doi:10.5539/elt.v7n5p59 URL: http://dx.doi.org/10.5539/elt.v7n5p59

\begin{abstract}
The present study was intended to examine the effects of 1) fields of study (arts, business and science-oriented); and 2) language-learning experiences (whether limited or non-limited to formal classroom instructions) on the use of VLSs among Thai tertiary-level students. The participants were 905 Thai EFL students studying in the Northeast of Thailand. The VLS questionnaire was employed for data collection. Descriptive statistics, an Analysis of Variance (ANOVA) and the chi-square tests were performed for data analysis. The results revealed that fields of study and prior language-learning experiences affected the students' overall VLS use, use of VLSs by the category and the individual strategy levels. The variation patterns of students' VLS use were found in relation to the two variables.
\end{abstract}

Keywords: vocabulary learning strategies, fields of study, language-learning experiences

\section{Introduction}

In learning any languages, vocabulary seems to be a major focal point of acquisition (Asgari \& Mustapha, 2011). In the context of teaching English as a second (ESL) or a foreign language (EFL), vocabulary plays a key role in the language learning process as it is one of the important language elements that can support all of the four skills, i.e., speaking, listening, reading and writing. For L2 learners, vocabulary is considered a key to understand what they are reading as Nation (2009) points out that reading requires knowledge and skill. This knowledge includes recognising the letters and words of the language, having substantial vocabulary, grammatical and textual knowledge. In addition, the reader must be able to bring knowledge of the word to the reading task. Tertiary-level students are expected to be able to read general English texts and the texts related to their fields of study. With adequate vocabulary knowledge in the target language, the students are able to cope with their reading. On the other hand, students having insufficient vocabulary knowledge might face numerous problems in comprehending and producing other skills in the target language (A. Jahan \& N. Jahan, 2011). According to Stæhr (2008, p. 1), "vocabulary knowledge is generally assumed to be a good predictor of language proficiency in a second or a foreign language." Clearly, one of the factors that might hinder tertiary-level students' language performance is the inadequacy of their vocabulary knowledge.

In the context of teaching English as a foreign language at the tertiary level in Thailand, some students are likely to learn and memorise a new word once it has been indirectly taught. Others may look up the meaning of new words they encounter in a bilingual dictionary. It is noted that these students may easily forget the new words they come across. It is necessary for them to hear and use the vocabulary repeatedly before they are able to acquire the vocabulary items. The fact is that Thai EFL students do not avail themselves of the many opportunities there are to experience English language. For these students, vocabulary learning strategies (VLSs) may help facilitate their vocabulary learning; for example, Nation (2001) has asserted that a large and rich vocabulary can be acquired with the help of VLSs. Different learners may employ different techniques or strategies to learn vocabulary. What remains under-researched is how the individual EFL tertiary level students in Thailand deal with their own vocabulary learning. Understanding a comprehensive picture of students' VLS use might enable EFL teachers to improve the vocabulary teaching methods as well as increase the awareness of those factors that may have an impact on the students' VLS use. For EFL students, the results of the present 
study may benefit them in terms of identifying those VLSs they have already employed and those they may have never used, pointing out the factors that may contribute to becoming a strategic vocabulary learner.

\subsection{Research Questions}

The present study was conducted to examine the effects of fields of study and language-learning experiences on the VLSs reported being employed by students studying at the tertiary level in the Northeast of Thailand. Specifically, the research was designed to answer the following questions: 1) What is the frequency of the VLSs reported being employed by Thai tertiary-level students in relation to their fields of study and language-learning experiences 2) Do the students' choices of VLSs vary significantly with their fields of study and languagelearning experiences? If they do, what are the main patterns of variation?

\section{Research Methodology}

Four aspects regarding the research methodology are presented in the subsequent sections.

\subsection{Terms Used in the Present Study}

\subsubsection{Vocabulary Learning Strategies}

The term "vocabulary learning strategies" refers to as any set of techniques, including actions or mental processes that Thai students studying at the tertiary level reported employing in order to facilitate their English vocabulary learning with the purpose of enhancing their vocabulary knowledge.

\subsubsection{Tertiary-Level Students}

The term "tertiary-level students" refers to undergraduate students who have been studying in a regular programme on offer at the four types of institutions. The four types of institution have been offering a formal education mainly for the tertiary level. They are public/autonomous public university, private college/ university, Rajabhat University and Rajamangala University of Technology.

\subsubsection{Fields of Study}

"Fields of study" refers to the three fields of study of which all the four types of institutions have been offering for the students to study. They are arts-oriented, science-oriented and business-oriented fields.

\subsubsection{Language-Learning Experiences}

Language-learning experiences are classified as limited and non-limited to formal classroom instructions. The students whose language-learning experiences are "limited to formal classroom instructions" refers to the students who have an exposure to the English language within the formal classroom instructions only or hardly ever have an exposure to the English language beyond the formal classroom instructions. The students whose language-learning experiences are "not limited to the formal classroom instructions" refers those who have an exposure to the English language within and beyond the formal classroom instructions.

\subsection{Participants and Sampling Procedures}

As the population under this study was the students studying at the four different types of institutions (33 institutions), stratified and purposive sampling techniques were employed to select the participants. A total of 905 students from 11 institutions participated in the study. (see Table 1)

Table 1. Numbers of research participants by types of institution in terms of fields of study and language-learning experiences

\begin{tabular}{llllll}
\hline Types of Institution & \multicolumn{2}{c}{ Fields of Study } & \multicolumn{3}{c}{$\begin{array}{l}\text { Language-Learning } \\
\text { Experiences }\end{array}$} \\
\hline & Arts & $\mathrm{Bu}$ & $\mathrm{Sci}$ & $\mathrm{Non}-\mathrm{Li}$ & $\mathrm{Li}$ \\
\hline 2 public/autonomous public universities $(\mathrm{N}=230)$ & 98 & 43 & 89 & 170 & 60 \\
3 private colleges/universities $(\mathrm{N}=276)$ & 100 & 96 & 80 & 146 & 130 \\
4 Rajabhat Universities $(\mathrm{N}=253)$ & 110 & 94 & 49 & 103 & 150 \\
2 Rajamangala Universities of Technology $(\mathrm{N}=146)$ & 61 & 37 & 48 & 51 & 95 \\
\hline
\end{tabular}

Of the 905 participants, 230 were from two public/autonomous public universities (Suranaree University of Technology, and Khon Kaen University), 276 participants from three private colleges/universities (Nakhon 
Ratchasima College, College of Asian Scholars and Vongchavalitkul University), 253 participants from four Rajabhat Universities (Buriram, Mahasarakham, Roi-Et and Udonthani), and 146 participants from two Rajamangala Universities of Technology (Nakhon Ratchasima Campus and Sakonnakhon Campus).

\subsection{Instruments}

A 4-point rating scale VLS questionnaire in which "never" was scored as 1, "sometimes" as 2, "often" as 3 and "always or almost always" as 4, was employed to collect the data. The main VLS items were modified from Intaraprasert (2004) and Siriwan (2007). A few VLS items were modified from Schmitt (1997), Pemberton (2003) and Wink and Adulh (2007). Some VLSs were adopted without modification (16 items), the others were adapted (24 items). Examples are presented below:

Category 1: Adopted Items without Modification

Look at real objects and associate them with vocabulary items (from Siriwan, 2007)

Use new words in writing (from Intaraprasert, 2004)

Category 2: Slightly Changed Items

Before changed:

Write vocabulary items with meanings on papers and stick them in one's bedroom (from Siriwan, 2007)

After changed:

Write vocabulary items with meanings on papers and stick them on the wall in one's room (from Siriwan, 2007)

The English questionnaire version was translated into Thai to ensure the accuracy of the research results. The piloting of the VLS questionnaire was carried out in March 2013 to uncover any problems so that the researcher could make the necessary revision before the main stage was carried out. A written questionnaire was piloted with 40 students studying at Suranaree University of Technology and Vongchavalitkul University. Having been piloted, it was found that some wordings in the VLS questionnaire were ambiguous and needed refinement. Having been refined, the VLS questionnaire was ready to be used in the main stage. In the main stage, Alpha Coefficient $(\alpha)$ or Cronbach alpha was used to check the internal consistency of the questionnaire. The reliability estimate based on a 905 -student sample in the main stage was .94, when compared with the reliability coefficient of .70, which is the rule of thumb for research purpose (Fraenkel \& Wallen, 2000). (See Table 2)

Table 2. Reliability estimate of VLS questionnaire as a whole and in three main categories (DMV, RKV and EKV)

\begin{tabular}{lllll}
\hline VLS questionnaire & Whole VLSs & VLSs in DMV & VLSs in RKV & VLSs in EKV \\
\hline $\begin{array}{l}\text { Reliability Estimate } \\
\text { (Alpha Coefficient) }\end{array}$ & .94 & .81 & .88 & .86 \\
\hline
\end{tabular}

\subsection{Data Analysis}

Data obtained through the VLS questionnaire were analysed at three different levels: 1) overall VLS use; 2) use of overall VLSs by the three main categories, including the Discovery of Meaning or Other Aspects of New Vocabulary Items (DMV), the Retention of the Knowledge of Newly-Learned Vocabulary Items (RKV) and the Expansion of Knowledge of Vocabulary Items (EKV), and 3) use of 40 individual VLSs. The following statistics were performed to analyse the data using the SPSS Version 17.0.

\subsubsection{Descriptive Statistics}

Descriptive statistics was employed to describe the students' VLS use for two levels; the overall VLS use and use of overall VLSs by the category level. The students' VLS use was described in terms of mean and its S.D.

\subsubsection{An Analysis of Variance (ANOVA) and the Post-Hoc ScheffÉ Test}

ANOVA was performed to assess the overall VLS use in relation to the two variables. If there was a situation in which the researcher obtained significant differences among the variables with more than two levels, like fields of study, then the exploration of the differences among the means was needed by the post hoc Scheffé test.

\subsubsection{Chi-Square Test}

The chi-square test was used to examine the significant variation patterns at the individual VLS level. For the 
chi-square test facilitated by SPSS program, the responses of 1 and 2 ("Never" and "Sometimes") provided by the participants were consolidated into "low strategy use" category, while the responses of 3 and 4 ("Often" and "Always" or "Almost always") were consolidated into "high strategy use" category.

\section{Findings}

Findings are presented according to the three different levels of data analysis, the overall VLS use, use of VLSs by the three main categories and use of the individual VLS level. Each of the three levels is presented in relation to the students' fields of study and language-learning experiences.

\subsection{Variation in the Students' Reported Overall VLS Use}

Table 3. Summary of the students' reported overall VLS use

\begin{tabular}{lllllll}
\hline Variable & & Number & Mean & S.D. & Sig. Level & Variation Pattern \\
\hline 1. Fields of study & arts-oriented & 369 & 2.36 & .43 & $\mathrm{P}<.001$ & Arts $>$ Bu, Arts $>$ Sci \\
& business-oriented & 270 & 2.17 & .38 & & \\
& science-oriented & 266 & 2.19 & .39 & & \\
\hline 2. Experiences & non-limited & 470 & 2.40 & .41 & $\mathrm{P}<.001$ & Non-Limited $>$ Limited \\
& limited & 435 & 2.09 & .36 & & \\
\hline
\end{tabular}

As revealed in Table 3, the arts-oriented students reported employing VLSs significantly more frequently than the business and science-oriented students in the overall VLS use with the mean frequency scores of 2.36, 2.17 and 2.19, respectively. However, no significant differences in the use of VLSs were found between the business and science-oriented students. Concerning language-learning experiences, the students who have an exposure to the English language within and beyond the formal classroom instructions reported employing VLSs significantly more frequently than those who have an exposure to the English language within the formal classroom instructions only, with the mean frequency score of 2.40, and 2.09, respectively.

\subsection{Variation in the Students' Reported Use of VLSs by the Three Categories}

Table 4. Variation in the students' reported use of VLSs by the DMV, RKV and EKV categories according to fields of study

\begin{tabular}{lllllllll}
\hline \multirow{2}{*}{ Category } & Arts & \multicolumn{5}{c}{ Business } & \multicolumn{3}{c}{ Science } & \multirow{2}{*}{ Sig.Level } & \multirow{2}{*}{ Pattern of Variation } \\
\cline { 2 - 6 } & Mean & S.D. & Mean & S.D. & Mean & S.D. & & \\
\hline 1) DMV & 2.61 & .54 & 2.38 & .44 & 2.42 & .47 & $\mathrm{P}<.001$ & Arts $>$ Bu, Arts $>$ Sci \\
2) RKV & 2.17 & .44 & 2.01 & .40 & 2.05 & .41 & $\mathrm{P}<.001$ & Arts $>$ Bu, Arts $>$ Sci \\
3) EKV & 2.45 & .46 & 2.26 & .41 & 2.22 & .41 & $\mathrm{P}<.001$ & Arts $>$ Bu, Arts $>$ Sci \\
\hline
\end{tabular}

As shown in Table 4, the arts-oriented students reported employing VLSs significantly more frequently than the business and science-oriented students in the DMV, RKV and EKV categories. On the other hand, no significant differences in the use of VLSs were found between the business and science-oriented students in all three categories.

Table 5. Variation in the students' reported use of VLSs by the DMV, RKV and EKV categories according to language-learning experiences

\begin{tabular}{lllllll}
\hline \multirow{2}{*}{ Category } & \multicolumn{2}{l}{ Non-limited } & \multicolumn{2}{l}{ Limited } & \multirow{2}{*}{ Sig. Level } & Variation Pattern \\
\cline { 2 - 5 } & Mean & S.D. & Mean & S.D. & & \\
\hline 1) DMV & 2.66 & .49 & 2.30 & .44 & $\mathrm{P}<.001$ & Non-limited $>$ Limited \\
2) RKV & 2.22 & .43 & 1.94 & .39 & $\mathrm{P}<.001$ & Non-limited $>$ Limited \\
3) EKV & 2.48 & .44 & 2.15 & .37 & $\mathrm{P}<.001$ & Non-limited $>$ Limited \\
\hline
\end{tabular}


In relation to experiences, the students who have an exposure to the English language within and beyond the formal classroom instructions reported employing VLSs significantly more frequently than those who have an exposure to the English language within the formal classroom instructions in the DMV, RKV and EKV categories.

\subsection{Variation in the Students' Reported Use of Individual VLS Level}

Table 6. Variation in the students' reported use of individual VLSs according to fields of study

\begin{tabular}{|c|c|c|c|c|}
\hline Individual VLS Use & $\%$ of & gh Us & or 4$)$ & Ohcorrod $2^{2}$ \\
\hline Used more by Arts $>$ Sci $>$ Bu (16 VLSs) & Arts & Sci & $\mathrm{Bu}$ & ousctived $x$ \\
\hline $\begin{array}{l}\text { 1. EKV7 Attending classes of every module regularly to expand } \\
\text { knowledge of vocabulary items }\end{array}$ & 82.6 & 80.8 & 73.2 & $x^{2}=8.97 *$ \\
\hline $\begin{array}{l}\text { 2. DMV5 Using a dictionary to discover the meaning or other } \\
\text { aspects of vocabulary items }\end{array}$ & 73.8 & 59.0 & 57.0 & $x^{2}=24.16^{* * *}$ \\
\hline $\begin{array}{l}\text { 3. EKV13 Singing or listening to English songs to expand } \\
\text { knowledge of vocabulary items }\end{array}$ & 73.0 & 57.1 & 50.7 & $x^{2}=36.08 * * *$ \\
\hline $\begin{array}{l}\text { 4. DMV6 Asking friends to discover the meaning or other } \\
\text { aspects of vocabulary item }\end{array}$ & 59.1 & 50.8 & 47.4 & $x^{2}=9.46^{* *}$ \\
\hline $\begin{array}{l}\text { 5. EKV15 Practicing vocabulary translation from Thai into } \\
\text { English and vice versa. }\end{array}$ & 58.9 & 40.6 & 40.1 & $x^{2}=30.01 * * *$ \\
\hline $\begin{array}{l}\text { 6. EKV3 Studying vocabulary items from advertisements, public } \\
\text { relations, notices, traffic signs, etc. to expand knowledge of } \\
\text { vocabulary items }\end{array}$ & 58.6 & 45.9 & 43.4 & $x^{2}=17.37 * * *$ \\
\hline $\begin{array}{l}\text { 7. RKV8 Associating pictures to vocabulary items to retain } \\
\text { knowledge of newly-learned vocabulary items }\end{array}$ & 48.0 & 40.2 & 38.2 & $x^{2}=7.02 *$ \\
\hline $\begin{array}{l}\text { 8. DMV2 Guessing the meaning from contexts, such as a single } \\
\text { vocabulary, grammatical structure of a sentence to discover the } \\
\text { meaning of vocabulary items }\end{array}$ & 44.7 & 39.8 & 32.7 & $x^{2}=9.35^{* *}$ \\
\hline $\begin{array}{l}\text { 9. DMV1 Guessing the meaning by analysing the structure of } \\
\text { words (prefixes, roots and suffixes) to discover meaning of } \\
\text { vocabulary items }\end{array}$ & 43.6 & 40.2 & 27.2 & $x^{2}=18.91^{* * *}$ \\
\hline $\begin{array}{l}\text { 10. EKV4 Studying vocabulary section in one's textbook to } \\
\text { expand knowledge of vocabulary items }\end{array}$ & 42.8 & 34.2 & 29.4 & $x^{2}=12.75^{* *}$ \\
\hline $\begin{array}{l}\text { 11. RKV9 Associating the target word in English with a word } \\
\text { that sounds similar in Thai language to retain knowledge of } \\
\text { newly-learned vocabulary items }\end{array}$ & 40.3 & 39.1 & 28.3 & $x^{2}=10.98 * *$ \\
\hline $\begin{array}{l}\text { 12. RKV7 Connecting newly-learned vocabulary items to one's } \\
\text { previous learning experience to retain knowledge of } \\
\text { newly-learned vocabulary items }\end{array}$ & 37.9 & 28.2 & 23.5 & $x^{2}=10.98 * *$ \\
\hline $\begin{array}{l}\text { 13. RKV6 Associating newly-learned vocabulary items with } \\
\text { previously-learned ones to retain knowledge of newly-learned } \\
\text { vocabulary items }\end{array}$ & 34.9 & 27.1 & 21.0 & $x^{2}=15.22 * * *$ \\
\hline $\begin{array}{l}\text { 14. EKV8 Learning words through literature, poems and } \\
\text { traditional culture to expand knowledge of vocabulary items }\end{array}$ & 34.6 & 22.2 & 19.9 & $x^{2}=21.09 * * *$ \\
\hline $\begin{array}{l}\text { 15. RKV10 Reviewing previous English lessons to retain } \\
\text { knowledge of newly-learned vocabulary items }\end{array}$ & 31.1 & 19.5 & 19.1 & $x^{2}=16.44 * * *$ \\
\hline $\begin{array}{l}\text { 16. EKV1 Playing English games, such as scrabble, crossword } \\
\text { puzzles to expand knowledge of vocabulary items }\end{array}$ & 28.9 & 26.7 & 18.8 & $x^{2}=8.96^{*}$ \\
\hline $\begin{array}{l}\text { 1. DMV4 Surfing the Internet to discover the meaning or other } \\
\text { aspects of vocabulary items }\end{array}$ & 67.3 & 56.6 & 53.0 & $x^{2}=14.85^{* *}$ \\
\hline $\begin{array}{l}\text { 2. EKV12 Watching an English-speaking film with subtitles to } \\
\text { expand knowledge of vocabulary items }\end{array}$ & 66.2 & 47.4 & 46.6 & $x^{2}=32.46^{* *}$ \\
\hline
\end{tabular}


3. DMV7 Asking teachers to discover the meaning or other aspects of vocabulary items

4. EKV10 Watching English programme channels or listening to English radio programmes to expand knowledge of vocabulary items

5. EKV11 Surfing the Internet, especially the websites for vocabulary learning to expand knowledge of vocabulary items

6. EKV6 Grouping words together according to the similarity of meanings, pronunciation, spelling or any other aspects that can link the words to be grouped together to expand knowledge of vocabulary items

7. EKV14 Listening to English lectures, presentation, or English conversation to expand knowledge of vocabulary items

8. RKV5 Using new words in writing to retain knowledge of newly-learned vocabulary items

9. DMV8 Asking other people or native speakers of English to discover meaning or other aspects of vocabulary items

10. RKV12 Using vocabulary items to converse with teachers of English or native speakers of English to retain knowledge of newly-learned vocabulary items

11. EKV2 Reading different types of different English printed material e.g. leaflets, brochures, textbooks, or newspapers to expand knowledge of vocabulary items

12. RKV11 Using vocabulary items to converse with friends to retain knowledge of newly-learned vocabulary items

13. RKV 13 Memorising with or without a word list to retain knowledge of newly-learned vocabulary items

14. RKV 14 Recording the words/phrases one is learning and playing them to oneself whenever one has some spare time to retain knowledge of newly-learned vocabulary items

15. EKV9 Taking an extra job or getting trained by the companies where one can use English, such as tour offices, hotels, etc. to expand knowledge of vocabulary items

1. EKV 5 Building a word network to expand knowledge of vocabulary items

1. RKV1 Saying or writing the word with its meaning repeatedly to retain knowledge of newly-learned vocabulary items
$48.8 \quad 34.6 \quad 33.5 \quad x^{2}=20.93 * *$

42.8

$34.9 \quad 25.6 \quad x^{2}=20.03^{*}$

$41.1 \quad 32.0 \quad 24.1 \quad x^{2}=20.58 * *$

$36.8 \quad 29.4 \quad 22.6 \quad x^{2}=14.93 * *$

$36.0 \quad 22.1 \quad 16.9 \quad x^{2}=32.38 * *$

$34.9 \quad 23.2 \quad 22.9 \quad x^{2}=15.20 * *$

$34.3 \quad 24.6 \quad 19.9 \quad x^{2}=17.45^{* *}$

$33.2 \quad 17.3 \quad 13.9 \quad x^{2}=39.44^{* *}$

$32.7 \quad 25.7 \quad 16.9 \quad x^{2}=19.99 * *$

$31.6 \quad 21.3 \quad 19.9 \quad x^{2}=14.13 * *$

$30.5 \quad 25.7 \quad 21.8 \quad x^{2}=6.13^{*}$

$21.3 \quad 14.3 \quad 9.8 \quad x^{2}=15.90 * *$

$16.3 \quad 11.4 \quad 7.5 \quad x^{2}=11.45^{* *}$

$12.9 \quad 7.6 \quad 4.5 \quad x^{2}=12.71 * *$

$19.5 \quad 15.8 \quad 9.6 \quad x^{2}=10.80 * *$

Note: $* \mathrm{P}<.05, \quad * * \mathrm{P}<.01, * * * \mathrm{P}<.001$

Table 6 demonstrates significant variations in use of individual VLSs in terms of fields of study. The results of the chi-square tests reveal four different variation patterns according to this variable

The first variation pattern, "Arts $>\mathrm{Sci}>\mathrm{Bu}$ " indicates that a significantly greater percentage of the arts-oriented students than the science and business-oriented students, reported employing high use of 16 VLSs. Three out of the 16 VLSs had a high reported frequency of use by more than 50 percent of the arts, science and business-oriented students. They are "Attending classes of every module regularly to expand knowledge of vocabulary items" (EKV 7), "Using a dictionary to discover meaning or other aspects of vocabulary items" (DMV 5), "Singing or listening to English songs to expand knowledge of vocabulary items" (EKV 13).

The second variation pattern, "Arts $>\mathrm{Bu}>$ Sci" indicates that a significantly greater percentage of the arts-oriented students than the business and science-oriented students, reported employing high use of 15 VLSs. One out of the 15 VLSs had a high reported frequency of use by more than 50 percent of the arts, business and science-oriented fields, i.e., "Surfing the Internet to discover the meaning or other aspects of vocabulary items" (DMV 4).

The third variation pattern is "Bu $>$ Arts $>$ Sci" indicating that a significantly greater percentage of the 
business-oriented students than the arts and science-oriented students, reported employing high use of 1 VLS, i.e. "Building a word network to expand knowledge of vocabulary items" (EKV5).

The last variation pattern is "Sci $>$ Arts $>$ Bu" indicating that a significantly greater percentage of the science-oriented students than the arts and business-oriented students, reported employing high use of 1 VLS, i.e. "Saying or writing the word with its meaning repeatedly to retain knowledge of newly-learned vocabulary items" (RKV1).

Table 7. Variation in the students' reported use of individual VLSs according to language-learning experiences

\begin{tabular}{|c|c|c|c|}
\hline Individual VLS Use & $\%$ of High Us & (3 or 4$)$ & 21 \\
\hline Used more by Non-Limited (39 VLSs) & Non-Limited & Limited & onserved $x$ \\
\hline $\begin{array}{l}\text { 1. EKV7 Attending classes of every module regularly to expand } \\
\text { knowledge of vocabulary items }\end{array}$ & 83.2 & 74.9 & $x^{2}=9.34^{* *}$ \\
\hline $\begin{array}{l}\text { 2. EKV13 Singing or listening to English songs to expand knowledge } \\
\text { of vocabulary items }\end{array}$ & 73.4 & 49.9 & $x^{2}=57.07 * * *$ \\
\hline $\begin{array}{l}\text { 3. DMV4 Surfing the Internet to discover the meaning or other } \\
\text { aspects of vocabulary items }\end{array}$ & 73.4 & 45.3 & $x^{2}=74.35^{* * *}$ \\
\hline $\begin{array}{l}\text { 4. DMV5 Using a dictionary to discover the meaning or other aspects } \\
\text { of vocabulary items }\end{array}$ & 71.3 & 57.0 & $x^{2}=20.06^{* * *}$ \\
\hline $\begin{array}{l}\text { 5. EKV12 Watching an English-speaking film with subtitles to } \\
\text { expand knowledge of vocabulary items }\end{array}$ & 67.9 & 40.7 & $x^{2}=63.39 * * *$ \\
\hline $\begin{array}{l}\text { 6. EKV3 Studying vocabulary items from advertisements, public } \\
\text { relations, notices, traffic signs, etc. to expand knowledge of } \\
\text { vocabulary items }\end{array}$ & 62.3 & 37.2 & $x^{2}=59.93 * * *$ \\
\hline $\begin{array}{l}\text { 7. DMV } 6 \text { Asking friends to discover the meaning or other aspects of } \\
\text { vocabulary items }\end{array}$ & 60.6 & 45.1 & $x^{2}=22.02 * * *$ \\
\hline $\begin{array}{l}\text { 8. EKV } 15 \text { Practicing vocabulary translation from Thai into English } \\
\text { and vice versa to expand knowledge of vocabulary items }\end{array}$ & 59.6 & 35.2 & $x^{2}=53.91 * * *$ \\
\hline $\begin{array}{l}\text { 9. DMV3 Guessing the meaning from contexts, such as pronunciation } \\
\text { and real situation to discover the meaning of vocabulary items }\end{array}$ & 54.3 & 29.0 & $x^{2}=59.28 * * *$ \\
\hline $\begin{array}{l}\text { 10. RKV } 8 \text { Associating pictures to vocabulary items to retain } \\
\text { knowledge of newly-learned vocabulary items }\end{array}$ & 51.7 & 33.1 & $x^{2}=31.93 * * *$ \\
\hline $\begin{array}{l}\text { 11. DMV2 Guessing the meaning from contexts, such as a single } \\
\text { vocabulary, grammatical structure of a sentence to discover the } \\
\text { meaning of vocabulary items }\end{array}$ & 51.1 & 27.4 & $x^{2}=53.05^{* * *}$ \\
\hline $\begin{array}{l}\text { 12. DMV1 Guessing the meaning by analysing the structure of words } \\
\text { (prefixes, roots and suffixes) to discover the meaning of vocabulary } \\
\text { items }\end{array}$ & 47.2 & 27.4 & $x^{2}=38.01 * * *$ \\
\hline $\begin{array}{l}\text { 13. EKV4 Studying vocabulary section in one's textbook to expand } \\
\text { knowledge of vocabulary items }\end{array}$ & 47.2 & 24.4 & $x^{2}=51.12 * * *$ \\
\hline $\begin{array}{l}\text { 14. DMV7 Asking teachers to discover the meaning or other aspects } \\
\text { of vocabulary items }\end{array}$ & 47.1 & 32.0 & $x^{2}=22.59 * * *$ \\
\hline $\begin{array}{l}\text { 15. EKV10 Watching English programme channels or listening to } \\
\text { English radio programmes to expand knowledge of vocabulary items }\end{array}$ & 45.7 & 24.1 & $x^{2}=46.14 * * *$ \\
\hline $\begin{array}{l}\text { 16. RKV9 Associating the target word in English with a word that } \\
\text { sounds similar in Thai language to retain knowledge of newly-learned } \\
\text { vocabulary items }\end{array}$ & 45.1 & 26.9 & $x^{2}=32.38 * * *$ \\
\hline $\begin{array}{l}\text { 17. EKV6 Doing extra English exercises or tests from different } \\
\text { sources, such as texts, magazines, internets, etc to expand knowledge } \\
\text { of vocabulary items }\end{array}$ & 40.0 & 20.0 & $x^{2}=42.72 * * *$ \\
\hline $\begin{array}{l}\text { 18. RKV7 Connecting newly-learned vocabulary items to one's } \\
\text { previous learning experience to retain knowledge of newly-learned } \\
\text { vocabulary items }\end{array}$ & 39.8 & 20.9 & $x^{2}=37.79 * * *$ \\
\hline
\end{tabular}


19. EKV11 Surfing the Internet, especially the websites for vocabulary learning to expand knowledge of vocabulary items

20. RKV5 Using new words in writing to retain knowledge of newly-learned vocabulary items

21. RKV6 Associating newly-learned vocabulary items with previously-learned ones to retain knowledge of newly-learned vocabulary items

22. EKV8 Learning words through literature, poems and traditional culture to expand knowledge of vocabulary items

23. EKV14 Listening to English lectures, presentation, or English conversation to expand knowledge of vocabulary items

24. RKV4 Looking at real objects and associating them with vocabulary items to retain knowledge of newly-learned vocabulary items

25. DMV8 Asking other people or native speakers of English to discover the meaning or other aspects of vocabulary items

26. RKV13 Memorising with or without a word list to retain knowledge of newly-learned vocabulary items

27. EKV 2 Reading different types of different English printed material e.g. leaflets, brochures, textbooks, or newspapers to expand knowledge of vocabulary items

28. EKV1 Playing English games, such as scrabble, crossword puzzles to expand knowledge of vocabulary items

29. RKV10 Reviewing previous English lessons to retain knowledge of newly-learned vocabulary items

30. RKV11 Using vocabulary items to converse with friends to retain knowledge of newly-learned vocabulary items

31. RKV10 Reviewing previous English lessons to retain knowledge of newly-learned vocabulary items

32. RKV6 Keeping a vocabulary notebook to retain knowledge of newly-learned vocabulary items

33. RKV17 Grouping words together according to the similarity of meanings, pronunciation, spelling or any other aspects that can link the words to be grouped together to retain knowledge of newly-learned vocabulary items

34. RKV1 Saying or writing the word with its meaning repeatedly to retain knowledge of newly-learned vocabulary items

35. RKV14 Recording the words/phrases one is learning and playing them to oneself whenever one has some spare time to retain knowledge of newly-learned vocabulary items

36. RKV3 Writing vocabulary items with meanings on papers and sticking them on the wall in one's room to retain knowledge of newly-learned vocabulary items

37. RKV15 Setting aside a regular time for vocabulary learning or memorising (e.g. just before going to bed) to retain knowledge of newly-learned vocabulary items

38. RKV2 Saying vocabulary items in rhymes to retain knowledge of newly-learned vocabulary items

39. EKV9 Taking an extra job or getting trained by the companies where one can use English, such as tour offices, hotels, etc. to expand knowledge of vocabulary items
39.4

39.1

38.3

35.3
26.9

$x^{2}=15.79 * * *$

$15.6 \quad x^{2}=62.18 * * *$

$17.7 \quad x^{2}=47.13 * * *$

17

$x^{2}=38.36^{* * *}$

16.3

$x^{2}=42.18^{* * *}$

17.5

$x^{2}=34.43 * *$

19.5

$x^{2}=24.71 * * *$

18.2

$x^{2}=30.03 * * *$

$17.2 \quad x^{2}=29.90 * * *$

17.0

$x^{2}=29.75^{* * *}$

$x^{2}=26.10^{* * *}$

$18.2 \quad x^{2}=21.36 * * *$

$16.6 \quad x^{2}=26.10 * * *$

$12.2 \quad x^{2}=16.17 * * *$

$12.4 \quad x^{2}=12.57 * * *$

$8.3 \quad x^{2}=29.90 * * *$

$11.0 \quad x^{2}=14.30 * * *$

$11.0 \quad x^{2}=8.96 * *$

$8.3 \quad x^{2}=17.42 * * *$

$7.6 \quad x^{2}=12.56 * * *$

$9.9 \quad x^{2}=4.41 *$ 
Table 7 reveals that a significantly greater percentage of students who have an exposure to the English language within and beyond the formal classroom instructions than those who have an exposure to the English language within the formal classroom instructions reported employing high use of 39 VLSs. Of the 39 VLSs, 11 VLSs had a high reported frequency of use by more than 50 percent of students who have an exposure to the English language within and beyond the formal classroom instructions. When compared with fields of study, the students' language-learning experiences seem to have stronger effects on the students' VLS use, with a larger proportion of significant variations in the students' use of individual strategies across the strategy questionnaire found to be related to this variable.

\section{Discussion}

The findings mentioned above were discussed as follows:

\subsection{Use of VLSs and Fields of Study}

Field of study has been considered one of the significant factors influencing students' VLS use. Some previous researchers have found significant differences in VLS use between students studying in different academic fields (Wei, 2007; Siriwan, 2007; Bernardo \& Gonzales, 2009; Tsai \& Chang, 2009). In the present study, the findings suggest that field of study was found to be one of the factors influencing VLS use. The arts-oriented students employed VLSs significantly more frequently than the business and science-oriented students in the overall VLS use, use of VLSs by the three main categories and use of VLSs at individual VLS level. On the other hand, the students in the business-oriented and the science-oriented fields did not differ in their VLS use. When taking a closer look at the arts-oriented field of study, around 50 percent (182 out of 369) of students studying in the arts-oriented field were English majors. The results of the present study are partly consistent with Liao (2004), Siriwan (2007), Wei (2007) and Yi (2010) in that English majors generally exceed non-English majors in the overall VLS use.

One of the possible explanations is their language learning motivation. Motivation in the context of L2 learning refers to "the effort which learners put into learning L2 as a result of their need or desire to learn it" (Ellis, 1994: 715). Empirical research work has discovered that English major students were more highly motivated in learning English language than those in non-English majors (Kell, 2005). In addition, empirical research work supports the link between students' motivation in language learning and their VLS use revealing that the more highly motivated learners employed a wider range of VLSs than those of lower motivation (Marttinent, 2008). As a result, the students in arts-oriented field reported employing a more variety and a greater frequency of VLSs than those in the business and science-oriented fields.

Even though the business and science-oriented students were not significantly different in terms of VLS use in the overall and the category levels, it is worth taking the individual level to be discussed. At the individual level, two dominant patterns, "Arts $>\mathrm{Sci}>\mathrm{Bu}$ " and "Arts $>\mathrm{Bu}>$ Sci" were found. The former pattern indicates a significantly greater percentage of the arts-oriented students than the science and business-oriented students, reporting high use of 16 VLSs. The latter variation pattern indicates a significantly greater percentage of the arts-oriented students than the business and science-oriented students, reporting high use of 15 VLSs. The interesting point worth to be discussed here is the differences of VLS use at the individual level between the business and science-oriented students. In those strategies related to discovering meaning or other aspects of vocabulary items and retaining the knowledge of newly-learned words, the business-oriented students tended to rely more on social strategies than did the science-oriented students. Examples are "Asking teachers to discover the meaning or other aspects of vocabulary items" (DMV 7), "Asking other people or native speakers of English to discover the meaning or other aspects of vocabulary items" (DMV 8), "Using vocabulary items to converse with teachers of English or native speakers of English to retain knowledge of newly-learned vocabulary items" (RKV12), "Using vocabulary items to converse with friends to retain knowledge of newly-learned vocabulary items" (RKV11). The science-oriented students tended to rely more on guessing to discover the meaning and making connections and associations to retain knowledge newly-learned words.

The differences at individual VLS use could be explained by the personal characteristics of students in these two different academic fields. The business-oriented students in the present study are students majoring in marketing, accounting, and banking and finance. Science-oriented students include science, nursing science and engineering students. According to Pringle, DuBose, and Yankey (2010) students in business administration fields are extroverted, and in particular students majoring in marketing are more extroverted than those in other business majors. This could explain why the business-oriented students rely more on social strategies when discovering the meaning and retain knowledge of newly learned words than those in science-oriented field.

The different personal characteristics of students in business and engineering fields were also found by 
Nagarjuna and Mamidenna (2008) revealing that students with an engineering background were more self-reliant, realistic, and responsible than those with commerce background. These characteristics can be found in the present study when the science-oriented students expanded their knowledge of vocabulary items by relying more on self-practice reliance strategies. Examples are "Practicing translating vocabulary from Thai into English and vice versa" (EKV 15), "Studying vocabulary items from advertisements, public relations, notices, traffic signs, etc." (EKV3), "Studying vocabulary section in one's textbook" (EKV 4), while business-oriented students are likely to rely more on media-reliance techniques, such as "Watching an English-speaking film with subtitles" (EKV12), "Watching English programme channels or listening to English radio programmes" (EKV 10), "Surfing the Internet, especially the websites for vocabulary learning" (EKV11), "Listening to English lectures, presentation, or English conversation" (EKV 14). The different personal characteristics of the students in science and business-oriented fields may influence their VLS use when they seek to discover the meaning, retain and expand the knowledge of vocabulary items.

\subsection{Use of VLSs and Language-Learning Experiences}

As mentioned earlier, language-learning experiences have been categorised in the present study into experiences that were limited or non-limited to formal-classroom instructions. The participants who have an exposure to the English language within the formal classroom instructions or hardly ever have an exposure to the English language beyond the formal classroom instructions were categorised as "limited to formal classroom instructions" (herein, "limited"), while the participants who have an exposure to the English language within and beyond the formal classroom instructions were categorised as "non-limited to formal classroom instructions" (herein, "non-limited"). To the best of the researcher's knowledge, no empirical research work has taken this variable into consideration as a factor that might affect the students' VLS use. However, in Siriwan's study (2007), the variable, namely previous language learning experience seems to be closely related to the variable being investigated in the present study. In that study, the previous language learning experiences were classified into "more" and "less" experienced based on the completion of the fundamental English 1 and 2 courses. Siriwan found that previous language learning experience was one of the key factors affecting the students' VLS use. The findings of the present study extend what has been found by Siriwan. In the present study, the students who have an exposure to the English language within and beyond the formal classroom instructions reported employing VLSs significantly more frequently than those who have an exposure to the English language within the formal classroom instructions in the overall VLS use, use of VLSs by the three main categories and use of VLS at the individual strategy level. In particular, 39 VLS items were found to be significantly different at this level. The findings of the present study suggest the strong effects of language-learning experience on VLS use.

The possible explanation for such strong effects of the students' language-learning experiences on their VLS use is that outside the classroom, the role of the teacher may fade. Therefore, it is entirely up to the students to take control of their own learning. One of the effective ways for students to learn vocabulary is to take responsibility for their own learning and become autonomous learners who decide what words to learn, make decision about how to learn and revise them, seek out opportunities to use the language and keep up their motivation to keep on learning and using the language (Nation, 2008). The qualities of autonomous or self-regulated learners in students who have an exposure to the English language within and beyond the formal classroom instructions might be the explanatory factor for the high frequency of their VLS use.

The non-limited group is considered more skilled vocabulary learners than the limited group. Thus, it is possible that the non-limited group has learned how to discover, retain and expand the vocabulary items. These skills probably help them construct their VLSs. This is consistent with Afflerbach, Pearson, and Paris (2008, p. 365) that "skills make up strategies.... strategies require a skill set". Afflerbach et al. (2008) point out further that skills are used automatically, while strategies are used deliberately. The non-limited group in the present study applied a wide range of VLSs because they drew on strategies of skilled vocabulary learners. These skills were used consciously when they were encountering the vocabulary items. This situation has been supported by Paris, Wasik, and Turner (1991) stating that developing skills can be construed as a strategy whenever it was applied in conscious activation because strategies are "skills under consideration" (p. 611).

\section{Conclusion}

Conducted in a data-driven, systematic and non-judgmental descriptive manner, the present study contributed to the context of English language education at the tertiary-level in Thailand. It focused on the investigated variables, namely students' fields of study and language-learning experiences. The VLS questionnaire was employed for data collection. The results revealed that fields of study and language-learning experiences affected the students' overall VLS use, VLSs used by the category and individual strategy levels. It has been concluded 
that between the two variables, language-learning experiences were found to have stronger effects on the student's VLS use than the students' field of study, as it was found that $98 \%$ of VLS items in VLS questionnaire were significantly different according to this variable. Limiting one's study of language to formal classroom settings has been shown to be debilitating to one's skills to deal with new vocabulary items. The more varieties of learning experiences, the better are the skills to deal with the vocabulary items.

\section{Limitations of the Study and Suggestions for Further Research}

A written questionnaire was employed as the main research instrument to elicit the data concerning the students' strategy use. However, no research instrument has been accepted to be the best research method to elicit such data; therefore, the potential limitations related to the use of written questionnaire should be acknowledged: 1) the respondents might not be able to exactly recall what they had done when they were dealing with vocabulary items so, they might not exactly report their real VLS use 2) the responses might be inaccurate because of the difficulty involved in the respondents' evaluation of their own VLS use. It would be better if further research studies could employ other data collection methods, such as classroom observations, think-aloud and diaries to supplement the use of a single written questionnaire.

The present study has limited itself to study the use of VLSs in relation to the two independent variables, namely fields of study and language-learning experiences. Other variables, such as years of study, motivation, vocabulary size, language proficiency should be taken into consideration by further research.

In the present study, both probability and non-probability sampling techniques were employed to select the participants. Therefore the findings of the present study might not be able to generalise to the whole population which was a total of tertiary-level students studying in the Northeast of Thailand. The extension of research findings and conclusion were limited to the setting of the present study.

\section{Acknowledgements}

The authors would like to express their heartfelt gratitude to all research participants for their enthusiastic participation. The authors wish to extend their appreciation to all teachers who work as coordinators at all participating institutions. Without their help and cooperation, the completion of this study would be impossible.

\section{References}

Afflerbach, P., Pearson, D. P., \& Paris, S. (2008). Clarifying differences between reading skills and reading strategies. The Reading Teacher, 61(5), 364-373. http://dx.doi.org/10.1598/RT.61.5.1

Asgari, A., \& Mustapha, B. G. (2011). The type of vocabulary learning strategies used by ESL students in university Putra Malaysia. English Language Teaching, 4(2), 84-90. http://dx.doi.org/10.5539/elt.v4n2p84

Bernardo, A. S., \& Gonzales, T. H. (2009). Vocabulary learning strategies of Filipino college students across five Disciplines. TESOL Journal, 1, 17-27.

Fraenkel, J. R., \& Wallen, N. E. (2000). How to Design and Evaluate Research in Education. London: Mcgraw Hill.

Intaraprasert, C. (2004). ETS Students and Vocabulary Learning Strategies: A Preliminary Investigation (Unpublished Research, Suranaree University of Technology, Nakhon Ratchasima, Thailand).

Jahan, A., \& Jahan, N. (2011). Working with vocabulary at tertiary level in Bangladesh. Journal of Education and Practice, 2(5), 45-57.

Kelly, M. (2005). Motivation, the Japanese freshman university student and foreign language acquisition. JALT Hokkaido Journal, 9, 32-47.

Liao, Y. F. (2004). A survey study of Taiwan EFL freshmen vocabulary learning strategies. Journal of National Pin-Tung Normal College, 21, 271-288.

Marttinen, M. (2008). Vocabulary Learning Strategies Used by Upper Secondary School Students Studying English as a Second Language (Unpublished Master Thesis, University of Jyvaskyla, Finland).

Nagarjuna, V. L., \& Mamidenna, S. (2008). Personality characteristics of commerce and engineering graduates-A comparative Study. Journal of the Indian Academy of Applied Psychology, 34(2), 303-308.

Nation, I. S. P. (2001). Learning Vocabulary in Another Language. Cambridge: Cambridge University Press. http://dx.doi.org/10.101

Nation, I. S. P. (2008). Teaching Vocabulary Strategies and Techniques. Boston: Sherrise Roehr.

Nation, I. S. P. (2009). Teaching ESL/ EFL Reading and Writing. New York: Routledge. 
Paris, S. G., Wasik, B. A., \& Turner, J. C. (1991). The development of strategic reading. In R. Barr, M. L. Kamil, P. B. Mosenthal, \& P. D. Pearson (Eds.), Handbook of Reading Research (Vol. 2, pp. 609-640). New York: Longman.

Pemberton, R. (2003). Remembering Vocabulary. Retrieved from http://lc.ust.hk/ sac/advice/english/vocabulary/ V4.htm

Pringle, C. D., DuBose, P. B., \& Yankey, M. D. (2010). Personality characteristics and choice of academic major: Are traditional stereotypes obsolete? College Student Journal, 44(1), 131-142.

Schmitt, N. (1997). Vocabulary learning strategies. In N. Schmitt, \& M. McCarthy (Eds.), Vocabulary: Description Acquisition and Pedagogy (pp. 199-228). Cambridge: Cambridge University Press.

Siriwan, M. (2007). English Vocabulary Learning Strategies Employed by Rajabhat University Students (Unpublished Doctoral Dissertation, Suranaree University of Technology, Thailand).

Stæhr, L. S. (2008). Vocabulary size and the skills of listening, reading and writing. Language Learning Journal, 36(2), 139-152. http://dx.doi.org/10.1080/09571730802389975

Tsai, C., \& Chang, I. (2009). An examination of EFLvocabulary learning strategies of students at the University of Technology of Taiwan. International Forum of Teaching and Studies, 5(2), 32-38.

Wei, M. (2007). An examination of vocabulary learning of college-level learners of English in China. The Asian EFL Journal, 9(2), 93-114.

Winke, P. M., \& Abduhl, R. (2007). Taking a closer look at vocabulary learning strategies: A case study of a Chinese foreign language class. Foreign Language Annals, 40(4), 697-712. http://dx.doi.org/10.1111/j.1944-9720.2007.tb02888.x

Huang, S. Y. (2010). Effects of Major and Gender Differences on Vocabulary Strategy Use (Unpublished Master thesis, National Pingtung Institute of Commerce, Taiwan).

\section{Copyrights}

Copyright for this article is retained by the author(s), with first publication rights granted to the journal.

This is an open-access article distributed under the terms and conditions of the Creative Commons Attribution license (http://creativecommons.org/licenses/by/3.0/). 